\title{
Glioblastoma: approach to treat elderly patients
}

\author{
Glioblastoma: enfoque no tratamento de pacientes idosos
}

\author{
Luciola de Barros Pontes ${ }^{1}$, Theodora Karnakis ${ }^{2}$, Suzana Maria Fleury Malheiros ${ }^{3}$, Eduardo Weltman ${ }^{4}$, \\ Reynaldo André Brandt ${ }^{5}$, Rafael Aliosha Kaliks Guendelmann ${ }^{1}$
}

\begin{abstract}
Treating elderly cancer patients is a challenge for oncologists, especially considering the several therapeutic modalities in glioblastoma. Extensive tumor resection offers the best chance of local control. Adequate radiotherapy should always be given to elderly patients if they have undergone gross total resection and have maintained a good performance status. Rather than being ruled out, chemotherapy should be considered, and temozolomide is the chosen drug. A comprehensive geriatric assessment is a valuable tool to help guiding treatment decisions in elderly patients with glioblastoma.
\end{abstract}

Keywords:Glioblastoma/therapy; Aged;Geriatricassessment; Radiotherapy; Antineoplasic agents, alkylating/therapeutic use

\section{RESUMO}

0 tratamento de idosos com câncer é um desafio para a prática oncológica, especialmente no que se refere à terapêutica multimodal do glioblastoma. Nessa população, a ressecção ampla do tumor oferece a melhor chance de controle local e, naqueles pacientes que mantenham um bom performance status, a radioterapia complementar deve sempre ser levada em consideração. A quimioterapia também tem um papel no tratamento, sendo a temozolomida a droga de eleição. Frente à heterogeneidade desses pacientes, uma avaliação geriátrica ampla é um instrumento valioso no auxílio da decisão terapêutica em idosos com glioblastoma.

Descritores: Glioblastoma/terapia; Idoso; Avaliação geriátrica; Radioterapia; Antineoplásicos alquilantes/uso terapêutico

\section{INTRODUCTION}

The population throughout the world is ageing, and, as a consequence, cancer diagnosis is increasing. The incidence of cancer is eleven times higher in people older than 65 than in younger people. Seventy percent of cancer deaths occur in patients older than $70^{(1)}$. In the United States, approximately $50 \%$ of new cases of glioblastoma (GBM) occur in patients older than 65 , and in this patient population the incidence of GBM is about $13 / 100,000$ every year ${ }^{(2,3)}$.

Treating elderly cancer patients is a major challenge for most types of cancer, and different treatment modalities are controversial in the setting of an elderly patient with GBM. Very little data is published regarding treatment of GBM in an elderly patient population, and it is fairly common to see elderly patients with GBM being spared treatment modalities such as surgery, radiation therapy (RT) and systemic therapy, without a proper evaluation of their actual risks and benefits.

In this article, we undertook a non-systematic review of GBM in elderly patients, discussing prognosis, therapy and tools that are available and that could help select patients for the most appropriate intervention.

\section{Prognostic and predictive factors}

Advanced age is the most significant prognostic factor for elderly patients with GBM. For all patients with GBM, regardless of age, even when treated aggressively with surgery, radiation and chemotherapy, the median survival is around 15 months only ${ }^{(4)}$. In a study evaluating patients older than 70 years, the median survival among 3,298 patients was only 4 to 5 months ${ }^{(5)}$. The reasons for this apparently more aggressive course of the disease are not well understood. In a retrospective study of

\footnotetext{
'Department of Clinical Oncology, Hospital Israelita Albert Einstein - HIAE, São Paulo (SP) Brazil.

2 Department of Oncogeriatrics, Hospital Israelita Albert Einstein - HIAE, São Paulo (SP) Brazil.

${ }^{3}$ Department of Neuro-oncology, Hospital Israelita Albert Einstein - HIAE, São Paulo (SP) Brazil.

${ }^{4}$ Department of Radiotherapy, Hospital Israelita Albert Einstein - HIAE, São Paulo (SP) Brazil.

${ }^{5}$ Department of Neurosurgery, Hospital Israelita Albert Einstein - HIAE, São Paulo (SP) Brazil.

Corresponding author: Lucíola de Barros Pontes - Avenida Albert Einstein, 627 - Morumbi - Zip code: 05652000 - São Paulo (SP), Brazil - Phone: (55 11) 2151-0491 - E-mail: luciola.pontes@einstein.br

Received on: Jan 22, 2012 - Accepted on: Jul 30, 2012
} 
2,836 patients older than 70 years, only $46 \%$ received what was perceived to be standard therapy, namely surgery followed by radiotherapy, suggesting a large component of heterogeneous treatment as part of this worse prognosis ${ }^{(6)}$. Other likely culprits for the observed worse prognosis include higher number of co-morbid conditions and its consequent poly-pharmacy, drug interactions and higher toxicity from systemic therapy such as myelossupression, mucositis and cardiotoxicity, all leading to higher mortality ${ }^{(7)}$.

Methylation of the $\mathrm{O}^{6}$-methylguanine-DNA methyltransferase gene (MGMT) is known to be associated with a better response to temozolomide (TMZ); arguably the most common chemotherapy used in $\mathrm{GBM}^{(8)}$. MGMT is an important enzyme responsible for DNA repair such as that induced by TMZ and other alkylating agents. The epigenetic silencing of MGMT through the methylation of its promoter results in decreased DNA repair and better efficacy of chemotherapy ${ }^{(9)}$. Methylation of the promoter of MGMT is present in about $40 \%$ of GBM elderly patients, similar to the percentage found in younger patients ${ }^{(10)}$. Some data suggest that the predictive value of the methylation is present in the elderly as well. Minniti et al. ${ }^{(11)}$ identified 83 patients with GBM older than 70 years, with MGMT promoter methylation in $50 \%$ and a median survival of 15.3 months versus 10.3 months in those without methylation $(p=0.0001)$. Although some authors suggest to systematically use the promoter methylation of MGMT as a predictor of chemotherapy benefit, the evaluation of such methylation has not been well standardized. Additionally, there is fair evidence of intra-tumor variability in promoter methylation, as well as a change in methylation status induced by radiation therapy, suggesting caution in using this as a predictive marker $^{(12,13)}$.

Recent data have suggested that prognosis of patients with GBM is also determined by a complex interaction between age and several genetic alterations, as shown in table 1. Batchelor et al. ${ }^{(14)}$ demonstrated that genetic changes vary in different age groups. For patients older than 70 years, mutation in TP53 was associated with a shorter survival $(\mathrm{HR}=7.54 ; 95 \%$ confidence interval, 95\% CI: 2.38-23.87), while for patients younger than 70 years, this association with survival was not present (HR $=0.84$; 95\%CI: 0.49-1.42). Similarly, deletion of $\mathrm{CDKN} 2 \mathrm{~A} / \mathrm{p} 16$ was associated with a worse prognosis in patients older than 70 years $(\mathrm{HR}=11.48$; $95 \% \mathrm{CI}$ : 1.97 66.78). On the other hand, the positive prognostic value of the loss of chromosome 1p36 was more pronounced in patients older than 60 years of age $(\mathrm{HR}=0.1 ; 95 \% \mathrm{CI}$ : 0.01-0.78).

The epidermal growth factor receptor gene (EGFR) is frequently over expressed in GBM and its amplification is linked to disease progression. There are conflicting results about the prognostic implication of EGFR amplification. Opposite to the negative prognostic implication seen in younger individuals, in patients over 75 years of age, Kleinschmidt et al. ${ }^{(15)}$ demonstrated that those with amplified EGFR had a longer survival than those without the amplification (median 10.5 versus 2 months). Quan et al. ${ }^{(16)}$ failed to find any prognostic implication of EGFR amplification regardless of age.

Bredel et al. ${ }^{(17)}$ identified that deletion of NFKBIA, a gene responsible for inhibiting signaling through EGFR, is rather prevalent in some forms of GBM. This deletion is associated with higher tumor aggressiveness, less response to temozolomide and worse prognosis. There are no specific data on deletion of NFKBIA in elderly patients.

Other genetic changes were studied, such as the MIB-1 index and expression of protein YKL-4, with conflicting results ${ }^{(18)}$. Despite all these genetic correlations with GBM and age, it is still not clear whether older age has a worse prognosis related to specific genetic characteristics of the tumor or whether the prognosis is rather poor mainly due to other clinically relevant comorbid conditions.

Table 1. Molecular factors related to prognosis and age

\begin{tabular}{|c|c|c|c|}
\hline Author & Molecular factor & Age (years) & Prognostic implication \\
\hline Minniti et al. ${ }^{(11\}}$ & Methylation of the promoter of MGMT & $>70$ & Longer overall survival $(p=0.0001)$ \\
\hline Brandes et al..$^{(19)}$ & & $>65$ & Longer overall survival $(p=0.05)$ \\
\hline Batchelor et al. ${ }^{(14)}$ & Mutation p53 & $>70$ & Shorter overall survival $(p=0.001)$ \\
\hline Batchelor et al. ${ }^{(14)}$ & Deletion CDKN2A/p16 & $>70$ & Shorter overall survival $(p=0.024)$ \\
\hline Batchelor et al..(14) & Deletion 1p36 & $>60$ & Longer overall survival $(p=0.071)$ \\
\hline Kleinschmidt et al.(15) & Amplification EGFR & $>75$ & Longer overall survival ( $p=0.04)$ \\
\hline Quan et al..$^{(16)}$ & & $>60$ & No association with prognosis \\
\hline Bredel et al. ${ }^{(17)}$ & Deletion NFKBIA & * & Shorter overall survival $(p=0.03)$ \\
\hline
\end{tabular}

*The study included patients $>65$ years, but results specific to this population have not been published.

MGMT: methylation of the $0^{6}$-methylguanine-DNA methyltransferase gene; EGFR: epidermal growth factor receptor gene 


\section{Peculiarities of surgical treatment in the elderly}

In patients younger than 65 years of age, clinical evidence favor the most ample possible surgical resection with preservation of function ${ }^{(20)}$. In the elderly, aggressive surgery is performed less frequently, based mainly on a poor physiological reserve and the risk of perioperative complications.

Total or even partial resection confers a better prognosis than biopsy only. While ample resection confers a survival of up to 12 months, it rarely reaches 6 months after biopsy onlyy ${ }^{(21)}$. Ewelt et al. ${ }^{(22)}$ analyzed retrospectively data from 103 patients older than 65 years with GBM. In this cohort of patients, survival was closely related to the extent of the resection: biopsy only, partial resection, or total resection lead to 2.2 , 7 , and 13.9 months survival, respectively. Even when additional treatment with radiation and chemotherapy was taken into consideration, the difference in prognosis related to the extent of surgery remained significant. Therefore, until randomized prospective data is available, age alone should not be used as a contraindication for a more extensive resection.

Advances in neurosurgical technique, shorter duration of surgery and better peri-operative care made a more extensive resection feasible in the majority of patients. For patients who are surgical candidates, the following pre-operative findings were identified as predictors of a shorter survival: Karnofsky performance status (KPS) $<80$, chronic obstructive pulmonary disease, tumor $>4 \mathrm{~cm}$ associated with symptoms, such as motor, language or cognitive impairment ${ }^{(20)}$.

\section{RT peculiarities}

Postoperative RT is the standard treatment for GBM both after maximal debulking as well as after limited biopsy, conferring survival when compared to supportive care only ${ }^{(18)}$. RT not only improves survival, but it also helps in the control of tumor related symptoms. The most common RT treatment consists of 54 to $60 \mathrm{~Gy}$, divided into $2 \mathrm{~Gy}$ fractions over 5 to 6 weeks of treatment.

Efficacy of RT was first suggested in retrospective data from the Surveillance, Epidemiology and End Results (SEER) database involving 2,836 patients with GBM and older than 70 years, diagnosed between 1993 and 2005. The data showed that those patients who had received RT had a longer cancer- specific and overall survival compared to those who did not receive RT $(\mathrm{HR}=0.43 ; 95 \% \mathrm{CI}$ : 0.38-0.49). The median survival was 8 and 3 months, respectively ${ }^{(6)}$. These findings were subsequently confirmed in a prospective multicenter study published in 2007 by Keime-Guibert et al. ${ }^{(23)}$, involving 85 patients treated in 10 different medical centers in France. Patients were operated on and then randomized to receive RT (daily fractions of 1.8Gy for a total of 50Gy) or best supportive measures. The results favored RT, with a median survival of 29.1 versus 16.9 weeks (HR for death $=0.47 ; 95 \% \mathrm{CI}: 0.29-0.76 ; \mathrm{p}=0.002$ ). Despite the fact that elderly are more susceptible to adverse effects of RT to the brain tissue, in this study, no difference was observed in terms of cognitive function or quality of life between the two treatment groups. It is possible that the short survival may have prevented the documentation of the detrimental effects of RT. It seem the case in the practice of most neuro-oncologists that cognitive decline is caused by disease progression in the vast majority of cases ${ }^{(24)}$.

Alternative fractionation was studied aiming at a shorter course of RT, facilitating adherence and convenience to these frequently debilitated patients. Roa et al. ${ }^{(25)}$ randomized 100 patients with GBM and older than 60 years to receive standard RT (60Gy in 30 fractions, over 6 weeks) or an abbreviated course (40Gy

Table 2. Radiotherapy in treatment of elderly with glioblastomas

\begin{tabular}{|c|c|c|c|c|c|c|}
\hline Author & $\begin{array}{l}\text { Number of patients } \\
\text { and type of study }\end{array}$ & $\begin{array}{l}\text { Median } \\
\text { age }\end{array}$ & KPS & $\begin{array}{l}\text { Patients and extent } \\
\text { of surgery }\end{array}$ & RT versus control & Median overall survival \\
\hline Scott et al. ${ }^{(6)}$ & $\begin{array}{c}2,836 \\
\text { (retrospective) }\end{array}$ & $\begin{array}{c}76.9 \\
(71-98)\end{array}$ & $N R$ & $\begin{array}{c}\text { No surgery: } 31.5 \% \\
\text { Biopsy only: } 21.4 \% \\
\text { Partial or total: } 47.1 \%\end{array}$ & $\begin{array}{l}\text { RT after surgery: } 46.2 \% \\
\text { Surgery only: } 22.4 \%\end{array}$ & $\begin{array}{l}8 \text { months } \\
\text { versus } 3 \text { months } \\
\quad(p<0.001)\end{array}$ \\
\hline Keime-Guibert et al. ${ }^{\mid 23\}}$ & $\begin{array}{c}85 \\
\text { (randomized) }\end{array}$ & 73 & $>70$ & $\begin{array}{c}\text { Biopsy only: } 51.8 \% \\
\text { Partial: } 17.3 \% \\
\text { Total: } 30.9 \%\end{array}$ & $\begin{array}{l}50 \text { Gy (25F) versus supportive } \\
\text { care }\end{array}$ & $\begin{array}{l}29.1 \text { weeks versus } 16.9 \text { weeks } \\
\qquad(p=0.002)\end{array}$ \\
\hline Lutterbach et al. ${ }^{(26)}$ & $\begin{array}{c}96 \\
\text { (retrospective) }\end{array}$ & $67(60-81)$ & $>60$ & $\begin{array}{c}\text { Biopsy only: } 40.6 \% \\
\text { Partial + total: } 59.4 \%\end{array}$ & 60 Gy (30F) versus 42 Gy (12F) & $\begin{array}{l}5.6 \text { months versus } 7.3 \text { months } \\
\qquad(p=0.02)\end{array}$ \\
\hline
\end{tabular}

KPS: Karnofsky performance status; RT: radiotherapy; NR: not reported; F: fractions. 
in 15 fractions, over 3 weeks), with no concomitant chemotherapy. Median overall survival was 5.1 and 5.6 months, respectively for standard and short radiation treatment. These results were supported by retrospective data from Lutterbach and Ostertag ${ }^{(26)}$, who described a hypofractionated treatment of $42 \mathrm{~Gy}$ in 12 fractions, over 2.5 weeks, resulting in overall survival similar to that of traditional RT treatment ( 7.3 versus 5.6 months, respectively, $\mathrm{p}=0.2$ ). Table 2 summarizes the publications assessing at a geriatric patient population with GBM and treated with RT.

\section{Peculiarities of systemic treatment}

Treating elderly patients with chemotherapy is often controversial in most types of cancer, and GBM is no exception. Pharmacokynetics and pharmacodynamics of drugs are modified in the elderly for several reasons. Changes in intestinal motility, splancnic vascularization, secretion of digestive enzymes and mucosal atrophy can all interfere with drug absorption of oral drugs, such as $\mathrm{TMZ}$ and lomustine, some of the most frequently used chemotherapies in $\mathrm{GBM}^{(27)}$. The activity of cytochrome P450 diminished by 20 to $25 \%$ in the elderly, leading to inadequate metabolization of anti-seizure drugs, and these, on the other hand, can interfere with the metabolism of chemotherapeutical agents, such as irinotecan and procarbazine ${ }^{(28)}$. The decreased bone marrow reserve also predisposes elderly patients to a more severe myelosuppressive effect of chemotherapy drugs, favoring infections.

Results from a meta-analysis that included 12 randomized trials ${ }^{(29)}$ demonstrated that adjuvant chemotherapy improves overall survival in patients with high grade gliomas. Among the 3,004 patients included in this analysis, $28 \%$ were older than 60 years. This patient population had the same statistically significant benefit with chemotherapy than the overall population.

Although regimens including carmustine (BCNU) or the combination PCV (procarbazin, lomustine and vincristin) have led to somewhat longer overall survival in patients with GBM, due to their significant myelotoxicity, they should probably be avoided in the elderly population ${ }^{(30)}$.

TMZ is an alkylating agent with a rather safe toxicity profile. In the vast majority of clinical studies with the drug, less than $10 \%$ of patients developed Common Toxicity Criteria (CTC) grade 3 or 4 hematologic toxicity, and less than $2 \%$ of patients had to suspend the drug due to side effects ${ }^{(31)}$. The oral formulation and tolerability, in addition to a clearance independent of renal or hepatic function, have made TMZ a very acceptable drug for elderly patients.
The standard treatment for GBM, based on trials including always patients younger than 70 years, is surgery, followed by RT concomitant with TMZ $75 \mathrm{mg} /$ $\mathrm{m}^{2}$ per day followed by 12 cycles of adjuvant $\mathrm{TMZ}$ at 150 to $200 \mathrm{mg} / \mathrm{m}^{2}$ for 5 days every 28 days, for 6 to 12 months ${ }^{(4)}$. Although there is a lack of actual randomized data for this treatment in the elderly, most experts agree that TMZ associated with RT is well tolerated in elderly with KPS $>80^{(32,33)}$. Fiorica et al. ${ }^{(32)}$ published data on 42 patients with GBM and who were older than 65 years, who had received RT+TMZ followed by TMZ. With a median survival of 10.2 months, treatment was well tolerated. The vast majority $(69 \%)$ had no drug related toxicity, $23.8 \%$ had myelotoxicity (only $7 \%$ grade 3 ), and $16.7 \%$ presented neurologic toxicity, which was reversed with the use of steroids. No treatment related death was reported.

Minniti et al. $^{(34)}$ evaluated the use of TMZ concomitant with a shorter RT treatment. In this phase II trial, 71 patients older than 70 years, with recently diagnosed GBM and with a KPS $>60$, were treated with a short RT (40Gy in 15 fractions, over 3 weeks) with concomitant TMZ, followed by 12 months of adjuvant TMZ. Overall survival was 12.4 months; only one patient discontinued TMZ during RT due to grade 2 thrombocytopenia, and $8 \%$ discontinued adjuvant treatment due to myelotoxicity. The most common nonhematologic toxicities were fatigue (10\% during RT, $17 \%$ during adjuvant TMZ) and nausea (11\%).

One phase III trial (EORTC 26062-22061) is currently looking at TMZ concomitant with a short RT treatment versus isolated RT in patients older than 65 years ${ }^{(35)}$.

The question whether methylation status of the promoter of MGMT should be used as a means to select patients for TMZ treatment was discussed earlier in this review and no data specific to elderly patients is available.

For patients who are not candidates for RT due to pre-existing conditions such as dementia or previous strokes, isolated TMZ can be considered. Gállego Pérez-Larraya et al. ${ }^{(36)}$ selected patients older than 70 years and with a KPS $<70$, and gave TMZ alone at 150 to $200 \mathrm{mg} / \mathrm{m}^{2}$ per day, for 5 days, every 28 days, for a total of 12 cycles until disease progression. Among the patients, $91.4 \%$ were not surgically treated, $62.9 \%$ had a KPS of 60 . Although the median overall survival was only 25 weeks (95\% CI: 19 to 28 weeks), $51.5 \%$ achieved disease stabilization and, more importantly, $32.9 \%$ had an improvement of KPS of, at least, 20 points, with $25 \%$ becoming able to self-care. The median progression-free survival was 16.1 weeks (95\% CI: 10.2 to 20 weeks). 
There are no published data about the second line treatment for elderly patients with GBM. The studies on the combination of irinotecan and bevacizumab, which is a regimen frequently used for recurrent GBM, did not include patients aged over 70 years. Therefore, any decision regarding the treatment of recurrent GBM in the elderly, has to be carefully discussed with attention to co-morbid conditions (specifically those that predispose to cardiovascular events, a wellknown risk associated with the use of bevacizumab), functional capacity, location of relapse and patient preferences.

Bevacizumab is being studied in this patient population. A phase II trial (NCT 01149850) will look at the combination of bevacizumab and TMZ in newly diagnosed elderly patients with GBM and a KPS $>60^{(37)}$. The ARTE study (NCT01443676) will look at combination of bevacizumab and RT in newly diagnosed elderly patients with $\mathrm{GBM}^{(38)}$.

Table 3 summarizes the published data of TMZ plus RT in elderly patients.

Table 3. Temozolomide (TMZ) \pm radiotherapy $(\mathrm{RT})$ in elderly with glioblastomas

\begin{tabular}{|c|c|c|c|c|c|c|c|}
\hline Author & $\begin{array}{l}\text { Number of } \\
\text { patients }\end{array}$ & $\begin{array}{l}\text { Median } \\
\text { age }\end{array}$ & KPS & TMZ & RT & $\begin{array}{l}\text { Median } \\
\text { survival } \\
\text { (months) }\end{array}$ & Toxicity \\
\hline Fiorica et al. ${ }^{[32]}$ & 42 & $\begin{array}{c}71.2 \\
(65-85)\end{array}$ & $\begin{array}{l}80-100(45.2) \\
60-70(54.8)\end{array}$ & $75 \mathrm{mg} / \mathrm{m}^{2}$ concomitant with $\mathrm{RT}$ & $\begin{array}{l}45 \mathrm{~Gy} \\
(15 \mathrm{~F})\end{array}$ & 10.2 & $\begin{array}{c}\text { Hematological: } 23.8 \% \\
\text { Neurological symptoms: } 16.7 \%\end{array}$ \\
\hline Minniti et al. ${ }^{\mid 34)}$ & 71 & $\begin{array}{c}73 \\
(70-81)\end{array}$ & $\begin{array}{c}70 \\
(60-100)\end{array}$ & $\begin{array}{c}75 \mathrm{mg} / \mathrm{m}^{2} \text { concomitant with RT } \\
200 \mathrm{mg} / \mathrm{m}^{2} \mathrm{D} 1-5 \mathrm{q} 28 \text { days, } \\
\text { adjuvant }\end{array}$ & $\begin{array}{l}40 \mathrm{~Gy} \\
(15 \mathrm{~F})\end{array}$ & 12.4 & $\begin{array}{c}\text { Hematological grade } 3 \text { and } 4 \\
4 \% \text { concomitant } \\
21 \% \text { adjuvant } \\
\text { Fatigue grade } 2 \text { and } 3 \\
10 \% \text { concomitant } \\
17 \% \text { adjuvant }\end{array}$ \\
\hline Combs et al. ${ }^{(39)}$ & 43 & $\begin{array}{c}67 \\
(65-76)\end{array}$ & 70 & $\begin{array}{c}50-75 \mathrm{mg} / \mathrm{m}^{2} \text { concomitant } \\
\text { with RT }\end{array}$ & $\begin{array}{l}60 \mathrm{~Gy} \\
\text { (30F) }\end{array}$ & 11 & $\begin{array}{l}\text { Hematological: } 9 \% \\
\text { Rash: } 5 \%\end{array}$ \\
\hline Gállego Pérez-Larraya et al. ${ }^{36 \mid}$ & 70 & $\begin{array}{c}77 \\
(70-87)\end{array}$ & $\begin{array}{c}60 \\
(30-60)\end{array}$ & $150-200 \mathrm{mg} / \mathrm{m}^{2} \mathrm{D} 1-5 \mathrm{q} 28$ days & NR & 25 & $\begin{array}{c}\text { Neutropenia/thrombocytopenia Grade } 3 \\
\text { and } 4 \text { with } 13 \text { and } 14 \% \text {, respectively }\end{array}$ \\
\hline
\end{tabular}

KPS: Karnofsky performance status; NR: not reported; F: fractions.

\section{Comprehensive geriatric assessment as part of patient care}

The most striking challenge in treating elderly patients with cancer resides in the significant heterogeneity of this population. While some patients tolerate and benefit from standard treatment as well as younger patients, others will require dose reductions, delays and discontinuations of different therapeutical modalities. Identifying which and how patients should be treated can be facilitated by the use of a comprehensive geriatric assessment (CGA). CGA can discriminate better than chronological age or performance status which patients are candidates for more aggressive therapy ${ }^{(40)}$. The literature is limited regarding CGA in elderly patients with GBM either as stratification for clinical trials or as a tool to help clinical practice.

CGA consists of a thorough evaluation of comorbid conditions, functional status, nutritional status, social support, polypharmacy and cognition, as described in table $4^{(41,42)}$.

CGA results are closely related to prognosis of elderly patients in general, and it has also been found beneficial for assessment of life expectancy, prediction of treatment tolerance and definition of frailty for older cancer patients. Mortality at 2 years increases with lower functional status ${ }^{(43)}$, dementia and depression ${ }^{(44)}$.

Dependency for daily living activities, measured by the Instrumental Activities of Daily Living (IADL) scale, was associated with a worse tolerance to chemotherapy, the same having been shown for nutritional status and for social support ${ }^{(45)}$. The European Organization for Research and Treatment of Cancer (EORTC) recommends that patients be classified as frail, vulnerable or healthy ${ }^{(40)}$, based on CGA. This classification can assist in the decision on treatment selection, dose adjustments and supportive care measures. Since CGA results are based on dynamic scales, a new evaluation should be performed at the time of every new treatment decision.

The main limitation of CGA is the time required for administration, not only for the clinician, but also for the patient and caregivers. This has lead to the development of shorter screening tests that help the clinician direct comprehensive screening efforts to 
those elderly patients who may be more likely to require further assessment.

Table 4. Comprehensive geriatric assessment measures

\begin{tabular}{lc}
\hline Assessments & Instrument \\
\hline Dependency & ADL \\
Dependency & IADL \\
Depression & GDS \\
Cognition & MMSE \\
Co-morbidity & CCI \\
& OR \\
Nutrition & CIRS-G \\
& MNA \\
Mobility/falls & AND \\
Polypharmacy & BMl \\
\hline
\end{tabular}

EORTC elderly task force recommendations ${ }^{(40)}$.

ADL: Activities of Daily Living; IADL: Instrumental Activities of Daily Living; GDS: Geriatric Depression Scale; MMSE: Mini-Mental State Examination; CCI: Charlson Comorbidity Index; CIRS-G: Cumulative IIIness Rating Scale-Geriatric; MNA: Mini Nutritional Assessment; BMI: Body Mass Index; TUGT: Timed-Up-and-Go-Test.

\section{CONCLUSION}

Elderly patients seem to benefit and tolerate the same treatment than younger patients if they have a good performance status and limited comorbid conditions. For patients with a KPS $>70$, postoperative RT improves survival without causing cognitive decline. For patients with reduced performance status, a short RT treatment seems equivalent to the traditional RT. Although TMZ has not been prospectively studied in randomized trials in the elderly, subgroup analysis from a metanalysis suggests good tolerance and clinical benefit, especially for patients with MGMT promoter methylation. Molecular factors such as EGFR or NFKBIA mutations, and even MGMT promoter methylation seem to be able to better characterize the prognosis of individual tumors, but at this time, treatment decisions still seem to be more dependent on a thorough evaluation in the case of elderly patients. CGA seems to be a valuable tool in establishing the best treatment options for a given patient.

\section{REFERENCES}

1. Yancik R. Cancer burden in the aged: an epidemiologic and demographic overview. Cancer. 1997;80(7):1273-83

2. Fisher JL, Schwartzbaum JA, Wrensch M, Wiemels JL. Epidemiology of brain tumors. Neurol Clin. 2007;25(4):867-90, vii.

3. Central Brain Tumor Registry of the United States. CBTRUS statistical report: primary brain and central nervous system. Tumors diagnosed in the United States in 2004-2007 [Internet]. Hinsdale (IL): CBTRUS; 2011 [cited 2012 Out
10]. Available from: http://www.cbtrus.org/2011-NPCR-SEER/WEB-0407Report-3-3-2011.pdf

4. Stupp R, Mason WP, van den Bent MJ, Weller M, Fisher B, Taphoorn MJ, Belanger K, Brandes AA, Marosi C, Bogdahn U, Curschmann J, Janzer RC, Ludwin SK, Gorlia T, Allgeier A, Lacombe D, Cairncross JG, Eisenhauer E, Mirimanoff R0; European Organisation for Research and Treatment of Cancer Brain Tumor and Radiotherapy Groups; National Cancer Institute of Canada Clinical Trials Group. Radiotherapy plus concomitant and adjuvant temozolomide for glioblastoma. N Engl J Med. 2005;352(10):987-96.

5. Paszat L, Laperriere N, Groome P, Schulze K, Mackillop W, Holowaty E. A population-based study of glioblastoma multiforme. Int J Radiat Oncol Biol Phys. 2001;51(1):100-7.

6. Scott J, Tsai $Y Y$, Chinnaiyan P, Yu HH. Effectiveness of radiotherapy for elderly patients with gliobastoma. Int J Radiat Oncol Biol Phys. 2011;81(1): 206-10.

7. Lichtman SM, Wildiers $H$, Chatelut E, Steer C, Budman D, Morrison VA, Tranchand B, Shapira I, Aapro M; International Society of Geriatric Oncology Chemotherapy Taskforce. International Society of Geriatric Oncology Chemotherapy Taskforce: evaluation of chemotherapy in older patients-an analysis of the medical literature. J Clin Oncol. 2007;25(14):1832-43.

8. Hegi ME, Diserens AC, Gorlia T, Hamou MF, de Tribolet N, Weller M, et al. MGMT gene silencing and benefit from temozolomide in glioblastoma. N Eng J Med. 2005; 352(10):997-1003.

9. Esteller M, Garcia-Foncillas J, Andion E, Goodman SN, Hidalgo OF, Vanaclocha $V$, et al. Inactivation of the DNA-repair gene MGMT and the clinical response of gliomas to alkylating agents. N Engl J Med. 2000;343(19):1350-4.

10. Brandes AA, Franceschi E. Primary brain tumors in the elderly population. Curr Treat Options Neurol. 2011;3(4):427-35.

11. Minniti G, Salvati M, Arcella A, Buttarelli F, D'Elia A, Lanzetta G, et al. Correlation between $0^{6}$-methylguanine-DNA methyltransferase and survival in elderly patients with glioblastoma treated with radiotherapy plus concomitant and adjuvant temozolomide. J Neurooncol. 2011;102(2):311-6.

12. Parkinson JF, Wheeler HR, Clarkson A, McKenzie CA, Biggs MT, Little NS, et al. Variation of $\mathrm{O}(6)$-methylguanine-DNA methyltransferase (MGMT) promoter methylation in serial samples in glioblastoma. J Neurooncol. 2008; 87(1):71-8.

13. Jung TY, Jung S, Moon KS, Kim IY, Kang SS, Kim YH, et al. Changes of the 06-methylguanine-DNA methyltransferase promoter methylation and MGMT protein expression after adjuvant treatment in glioblastoma. Oncol Rep. 2010;23(5):1269-76.

14. Batchelor TT, Betensky RA, Esposito JM, Pham LD, Dorfman MV, Piscatelli N, et al. Age-dependent prognostic effects of genetic alterations in glioblastoma. Clin Cancer Res. 2004;10(1 Pt 1):228-33.

15. Kleinschmidt-DeMasters BK, Lillehei KO, Varella-Garcia M. Glioblastomas in the older old. Arch Pathol Lab Med. 2005;129(5):624-31.

16. Quan AL, Barnett GH, Lee SY, Vogelbaum MA, Toms SA, Staugaitis SM, et al. Epidermal growth factor receptor amplification does not have prognostic significance in patients with glioblastoma multiforme. Int J Radiat Oncol Biol Phys. 2005;63(3):695-703.

17. Bredel M, Scholtens DM, Yadav AK, Alvarez AA, Renfrow JJ, Chandler JP, et al. NFKBIA deletion in glioblastomas. N Eng J Med. 2011;364(7):627-37.

18. Brandes AA, Compostella A, Blatt V, Tosoni A. Glioblastoma in the elderly: current and future trends. Crit Rev Oncol Hematol. 2006;60(3):256-66.

19. Brandes AA, Franceschi E, Tosoni A, Benevento F, Scopece L, Mazzocchi $V$, et al. Temozolamide concomitant and adjuvant to radiotherapy in elderly patients with glioblastoma: correlation with MGMT promoter methylation status. Cancer. 2009;115(15):3512-8.

20. Chaichana KL, Chaichana KK, Olivi A, Weingart JD, Bennett R, Brem $H$, et al. Surgical outcomes for older patients with glioblastoma multiforme: preoperative factors associated with decreased survival. Clinical article. J Neurosurg. 2011;114(3):587-94.

21. Halperin EC. Malignant gliomas in older adults with poor prognostic signs. Getting nowhere, and taking a long time to do it. Oncology (Williston Park). 1995;9(3):229-34 . 
22. Ewelt C, Goeppert M, Rapp M, Steiger HJ, Stummer W, Sabel M. Glioblastoma multiforme of the elderly: the prognostic effect of ressection on survival. J Neurooncol. 2011;103(3):611-8.

23. Keime-Guibert F, Chinot 0 , Taillandier L, Cartalat-Carel S, Frenay M, Kantor G, Guillamo JS, Jadaud E, Colin P, Bondiau PY, Meneï P, Loiseau H, Bernier V, Honnorat J, Barrié M, Mokhtari K, Mazeron JJ, Bissery A, Delattre JY; Association of French-Speaking Neuro-Oncologists. Radiotherapy for glioblastoma in the elderly. N Eng J Med. 2007;356(15):1527-35.

24. Brown PD, Jensen AW, Felten SJ, Ballman KV, Schaefer PL, Jaeckle KA, et al. Detrimental effects of tumor progression on cognitive function of patients with high-grade glioma. J Clin Oncol. 2006;24(34):5427-33.

25. Roa W, Brasher PM, Bauman G, Anthes M, Bruera E, Chan A, et al. Abbreviated course of radiation therapy in older patients with glioblastoma multiforme: a prospective randomized clinical trial. J Clin Oncol. 2004;22(9):1583-8.

26. Lutterbach J, Ostertag $\mathrm{C}$. What is the appropriate radiotherapy protocol for older patients with newly diagnosed glioblastoma? J Clin Oncol. 2005; 23(12):2869-70.

27. Baker SD, Grochow LB. Pharmacology of cancer chemotherapy in the older person. Clin Geriatr Med. 1997;13(1):169-83.

28. Vestal RE. Aging and pharmacology. Cancer. 1997;80(7):1302-10.

29. Stewart LA. Chemotherapy in adult high-grade glioma: a systematic review and meta-analysis of individual patient data from 12 randomised trials. Lancet. 2002;359(9311):1011-8.

30. Pierga JY, Hoang-Xuan K, Feuvret L, Simon JM, Cornu P, Baillet F, et al. Treatment of malignant gliomas in the elderly. J Neurooncol. 1999;43(2):187-93.

31. Dinnes J, Cave C, Huang S, Milne R. A rapid and systematic review of the effectiveness of temozolomide for the treatment of recurrent malignant glioma. Br J Cancer. 2002;86(4):501-5

32. Fiorica F, Berretta M, Colosimo C, Stefanelli A, Ursino S, Zanet E, et al. Glioblastoma in the elderly patients: safety and efficacy of adjuvant radiotherapy with concomitant temozolomide. Arch Gerontol Geriatr. 2010; 51(1):31-5.

33. Gerstein J, Franz K, Steinbach JP, Seifert V, Fraunholz I, Weiss C, et al. Postoperative radiotherapy and concomitant temozolomide for elderly patients with glioblastoma. Radiother Oncol. 2010;97(3):382-6.

34. Minniti G, Lanzetta G, Scaringi C, Caporello P, Salvati M, Arcella A, et al. Phase II study of short-course radiotherapy plus concomitant and adjuvant temozolomide in elderly patients with glioblastoma. Int J Radiat Oncol Biol Phys. 2012;83(1):93-9.

35. National Cancer Institute of Canada (NCIC) Clinical Trials Group. Radiation therapy with or without temozolomide in treating older patients with newly diagnosed glioblastoma multiforme [Internet]. 2012 [cited 2012 Out 10]. Available from: http://clinicaltrials.gov/ct2/show/NCT00482677?term =NCT 00482677 grank $=1$

36. Gállego Pérez-Larraya J, Ducray F, Chinot 0, Catry-Thomas I, Taillandier L, Guillamo JS, et al. Temozolomide in elderly patients with newly diagnosed glioblastoma and poor performance status: an ANOCEF phase II trial. J Clin Oncol. 2011; 29(22):3050-5.

37. Jonsson Comprehensive Cancer Center. Bevacizumab and temozolomide in treating older patients with newly-diagnosed glioblastoma multiforme or gliosarcoma [Internet]. 2012 [cited 2012 Out 10]. Available from: http:// clinicaltrials.gov/ct2/show/NCT01149850

38. University of Zurich. Avastin Plus Radiotherapy in Elderly Patients With Glioblastoma (ARTE) [Internet]. 2012 [cited 2012 Out 10]. Available from: http://clinicaltrials.gov/ct2/show/NCT01443676

39. Combs SE, Wagner J, Bischof M, Welzel T, Wagner F, Debus J, et al Postoperative treatment of primary glioblastoma multiforme with radiation and concomitant temozolomide in elderly patients. Int $\mathrm{J}$ Radiat Oncol Biol Phys. 2008;70(4):987-92.

40. Pallis AG, Fortpied C, Wedding U, Van Nes MC, Penninckx B, Ring A, et al EORTC elderly task force position paper: approach to the older cancer patient. Eur J Cancer. 2010;46(9):1502-13.

41. Extermann M, Hurria A. Comprehensive geriatric assessment for older patients with cancer. J Clin Oncol. 2007;25(14):1824-31.

42. Carreca I, Balducci L, Extermann M. Cancer in the older person. Cancer Treat Rev. 2005;31(5):380-402.

43. Balducci L, Extermann M. Cancer and aging. An evolving panorama. Hemato Oncol Clin North Am. 2000;14(1):1-16.

44. Monfardini S, Balducci L. A comprehensive geriatric assessment (CGA) is necessary for the study and the management of cancer in the elderly. Eur $\mathrm{J}$ Cancer. 1999; 35(13)1771-2.

45. Monfardini S, Ferrucci L, Fratino L, del Lungo I, Serraino D, Zagonel V. Validation of a multidimensional evaluation scale for use in elderly cancer patients. Cancer. 1996; 77(2):395-401. 